\title{
FLOW CYTOMETRY FOLLOW-UP ANALYSIS \\ OF PERIPHERAL BLOOD LEUKOCYTE SUBPOPULATIONS IN CALVES EXPERIMENTALLY INFECTED WITH FIELD ISOLATES OF MYCOPLASMA BOVIS
}

\author{
Katarzyna DUdeK $^{1 *}$, Dariusz BednareK ${ }^{1}$, Ewelina SzaCAWA ${ }^{1}$, Ruben S. Rosales ${ }^{2}$ \\ and Roger D. AYLING ${ }^{2}$ \\ ${ }^{1}$ Department of Cattle and Sheep Diseases, National Veterinary Research Institute, \\ 57 Partyzantow Avenue, 24-100 Pulawy, Poland; ${ }^{2}$ Mycoplasma Team, Animal and Plant \\ Health Agency (Weybridge), Woodham Lane, Addlestone, Surrey, KT15 3NB, \\ United Kingdom
}

(Received 20 October 2014; accepted 17 February 2015)

\begin{abstract}
Changes in peripheral blood leukocyte subpopulations were investigated in calves challenged intratracheally with three different Mycoplasma bovis isolates in Groups E1, E2, and E3. The controls received a placebo. Blood samples were collected before challenge and then at days 1 to 7, 14, 21 and 28. White blood cells (WBC), polymorphonuclear leukocytes (PMNLs), lymphocytes (LYMs), monocytes, eosinophils and basophils (mid-size cells, MID), as well as $\mathrm{CD} 2^{+}, \mathrm{CD}^{+}, \mathrm{CD}^{+}$, $\mathrm{WC}^{+}$lymphocyte subsets with $\mathrm{CD} 4: \mathrm{CD} 8$ ratio were also analysed. A transient increase of WBC and PMNLs in all challenged calves was observed on day 1. Increased LYM counts were observed in E1 throughout the study, whereas in E2 the LYM counts were higher only between days 14 and 28, and consistently lower in E3. The MID count had broadly comparable values for all groups. Stimulation of the $\mathrm{CD}_{2}{ }^{+}$response was observed in E2 and E3 in contrast with E1 which had a lower $\mathrm{CD} 2^{+}$throughout. The $\mathrm{CD} 4^{+}$response was dominant in $\mathrm{E} 1$ and $\mathrm{E} 2$, whereas in $\mathrm{E} 3$ a parallel $\mathrm{CD} 4^{+}$and $\mathrm{CD} 8^{+}$stimulation was observed. The B-cell response $\left(\mathrm{WC}^{+}\right)$and an increased $\mathrm{CD} 4: \mathrm{CD} 8$ ratio was most apparent in E1. The main host responses to $M$. bovis infections are a stimulation of $\mathrm{CD}^{+}$cells and an enhancement of the $\mathrm{WC}^{+}$response.
\end{abstract}

Key words: Calf, Mycoplasma bovis, leukocytes, flow cytometry

The disease caused by Mycoplasma bovis in cattle is responsible for substantial economic losses to the farming industry around the world. Infection by M. bovis can cause bronchopneumonia, mastitis, arthritis, keratoconjunctivitis, otitis, meningitis, and reproductive disorders (Nicholas and Ayling, 2003). In Poland, 64.3 per cent of calves affected with bovine respiratory disease (BRD) were

${ }^{*}$ Corresponding author; E-mail: katarzyna.dudek@piwet.pulawy.pl; Phone: 0048 (081) 889-3021; Fax: 0048 (081) 886-2595 
found to be seropositive for M. bovis (Dudek and Bednarek, 2012). In other European countries the seropositivity rate ranged from 11 to 88 per cent (Le Grand et al., 2002; Ayling et al., 2004; Tenk et al., 2004; Radaelli et al., 2008; Pardon et al., 2011).

It has been reported that $M$. bovis can have both a stimulating and a suppressing effect on host immunity (Dudek et al., 2013). It stimulates activation of the acute phase response (APR) in infected calves as a consequence of a significant increase in the specific acute phase proteins (APPs) (Dudek et al., 2010, 2011a, 2013), proinflammatory cytokine production (Jungi et al., 1996), and activates the arachidonic acid cascade (Dudek et al., 2011b). In contrast, it has a modulating effect on different immune leukocyte functions including the production of reactive oxygen species (ROS), but this may vary with each mycoplasma isolate. The suppressive effects of $M$. bovis include impairment of ROS production by leukocytes, but without suppression of the general cellular metabolism of these cells (Wiggins et al., 2011), and an apoptotic effect on bovine lymphocytes has also been reported by Vanden Bush and Rosenbusch (2002).

This study evaluated changes in peripheral blood leukocyte subpopulations, as detected by flow cytometry, following experimental infection of healthy calves with three different $M$. bovis field isolates.

\section{Materials and methods}

The experimental procedures and animal management protocols were undertaken according to the detailed unified requirements of the Polish Local Ethics Committee for Animal Experimentation, which also meet the EU requirements.

Calves

Twenty-four calves of the Black and White breed, approximately 5 weeks old, were obtained from a typical commercial Polish dairy farm. Their suitability for use in the study was determined by serological and bacteriological examination for BRD pathogens. Three weeks before the experiment nasal swabs were taken from each calf, and standard bacterial culture methods were used to detect BRD bacterial pathogens including Mycoplasma and Pasteurella species. Serological tests for M. bovis used the Bio-X ELISA (Bio-X Diagnostics, Belgium), and tests for bovine respiratory syncytial virus (BRSV), parainfluenza-3 virus (PI3V), adenovirus type 3, bovine herpesvirus type 1 (BHV-1) and bovine viral diarrhoea virus (BVDV) were performed by the use of commercial respiratory ELISA kits (Bio-X Diagnostics, Belgium). The calves were randomly divided into four equal groups of six animals each: three experimental groups (E1, E2, E3) and a control group (C). Each group of calves was housed in individual pens and fed milk replacer, hay and water ad libitum. No antibiotic treatment was given. 


\section{Isolates}

The identification and purity of $M$. bovis isolates (1,2 and 3) used in this study were confirmed by PCR/DGGE using universal primers (McAuliffe et al., 2005). Isolate 1 was obtained from milk from a case of clinical mastitis in Poland. Isolate 2 was derived from the lungs of a 5-month-old pneumonic calf, and isolate 3 was obtained from bovine fetal stomach contents, both originating from England. Multilocus sequence typing (MLST) was also performed on these isolates using the method described by Rosales et al. (2015).

\section{Inoculum preparation}

Each M. bovis isolate was cultured in a total volume of $23 \mathrm{~mL}$ of Eaton's medium with gentle shaking (Nicholas and Baker, 1998) at $37{ }^{\circ} \mathrm{C}$ with $5 \% \mathrm{CO}_{2}$ for a total of five days. The cultures were centrifuged at $10,000 \mathrm{~g}$ for $40 \mathrm{~min}$ and then resuspended in sterile phosphate-buffered saline (PBS; pH $7.4 \pm 0.2$ ), in a volume of $23 \mathrm{~mL}$. The final concentrations of the $M$. bovis inocula were $1.98 \times$ $10^{7}, 1.65 \times 10^{7}$ and $1.58 \times 10^{7} \mathrm{CFU} / \mathrm{mL}$ for isolates 1,2 and 3, respectively. Each $M$. bovis inoculum used for the calf challenge was free from any toxin contamination.

\section{Inoculation}

The experimental calves were intratracheally challenged once with $23 \mathrm{~mL}$ of the inoculum. Isolate 1 was given to Group E1, isolate 2 to Group E2, and isolate 3 to Group E3. The control animals (Group C) received $23 \mathrm{~mL}$ of sterile PBS administered by the same route.

Blood samples for laboratory analysis were collected from the calves before inoculation (day 0 ), and then at daily intervals up to day 7 , and subsequently on days 14, 21 and 28. The blood samples were collected from the vena jugularis externa of calves into a 1-ml vacutainer with EDTA- $\mathrm{K}_{2}$ anticoagulant.

\section{Leukogram}

White blood cell (WBC) counts with leukocyte differentiation which included neutrophils (polymorphonuclear leukocyte count, PMNL), lymphocytes (total lymphocyte count, LYM) and total number of monocytes, eosinophils and basophils presenting as mid-size leukocyte count (MID) were determined using an automatic blood analyser (Auto Counter AC 920, Swelab Instrument).

\section{Immunophenotyping of peripheral blood lymphocytes}

Peripheral blood lymphocyte immunophenotyping was performed using a flow cytometer (Coulter Epics XL 4C, Beckman Coulter Company, USA) according to the Beckman Coulter Operator's Guide Procedure. T-cell $\left(\mathrm{CD} 2^{+}\right)$, T- 
helper $\left(\mathrm{CD} 4^{+}\right)$, T-cytotoxic suppressor $\left(\mathrm{CD} 8^{+}\right)$and $\mathrm{B}$-cell $\left(\mathrm{WC}^{+}\right)$antigens were determined using the monoclonal antibodies (mAbs) detailed in Table 1. To standardise this analysis, anti-CD45 and anti-CD14 mAbs were used. OptiLyse C standard procedures for the expression of $\mathrm{CD}$ markers were used for the analyses of whole blood. Briefly, the first step was an incubation of $50 \mu \mathrm{l}$ of sample with the appropriate $\mathrm{mAb}$ for $15 \mathrm{~min}$, followed by the addition of $250 \mu \mathrm{l}$ of lysing solution (OptiLyse C Lysing Solution, Beckman Coulter) and incubated again for $15 \mathrm{~min}$. The mixture was then washed once using PBS with 5\% inactivated fetal calf serum (FCS) and finally resuspended in $0.5 \mathrm{ml}$ of the same PBS with serum. For the analysis of $\mathrm{WC}^{+}$expression the procedure was modified by using a secondary $\mathrm{mAb}$, with a longer incubation time of $(55 \mathrm{~min})$ and additional cell washing, six times using PBS enriched with FCS. All steps during the sample incubation with different kinds of mAbs were performed strictly at room temperature $\left(18-25^{\circ} \mathrm{C}\right)$. A flow cytometer and a logarithmic amplifier were used to analyse the suspension of cells. The data were acquired as listmodes and analysed in a form of histograms using SYSTEM II 3.0 software. The Multigraph programme was used to provide additional calculation information and to display the data.

Table 1

Panel of monoclonal antibodies (mAbs) used in lymphocyte phenotyping

\begin{tabular}{lcccccc}
\hline Monoclonal antibody $^{*}$ & Host origin & Format & Clone & Type & Isotype & Kind \\
\hline Anti-bovine CD45 & mouse & FITC & CC1 & monoclonal & IgG1 & primary \\
$\begin{array}{l}\text { Cross-reacting } \\
\text { anti-human CD14 }\end{array}$ & mouse & RPE-Cy5 & $61 \mathrm{D} 3$ & monoclonal & IgG1 & primary \\
Anti-bovine CD2 & mouse & FITC & CC42 & monoclonal & IgG1 & primary \\
Anti-bovine CD4 & mouse & FITC & CC8 & monoclonal & IgG2a & primary \\
Anti-bovine CD8 & mouse & FITC & CC63 & monoclonal & IgG2a & primary \\
Anti-bovine WC4 & mouse & S/N & CC55 & monoclonal & IgG1 & primary \\
F(ab')2 anti-mouse & & & & & & \\
IgG & rabbit & FITC & - & polyclonal & polyclonal & secondary \\
& & & & & IgG & \\
\hline
\end{tabular}

" manufactured by AbD Serotec, a Bio-Rad Company

Statistics

The significant differences between the mean values recorded in the experimental and control groups were analysed using one-way analysis of variance (ANOVA) followed by Tukey's RIR post-hoc test, with a statistically significant level of $\mathrm{P}<0.05$ (STATISTICA 10.0 Software, StatSoft Poland). 


\section{Results}

\section{Status of calves}

No bacterial bovine respiratory disease pathogens were detected by bacterial culture. All calves lacked specific antibodies to M. bovis. In some of the animals antibodies developed to BRSV and PI3 viruses, but there was no evidence of seroconversion.

The effectiveness of calf inoculation using these M. bovis field isolates with clinical and microbiological examinations was described by Dudek et al. (2013). During the experimental study no clinical changes such as elevated rectal temperature (fever) and respiratory changes were reported in the control group. However, in all experimental calves the rectal temperature increased to an average value of $40.5^{\circ} \mathrm{C}$ during the first week of the study. Mild respiratory signs of sero-mucosal and mucosal nasal discharge with sporadic coughing were observed in all experimental groups. No other adverse clinical signs were observed and the calves were not euthanised.

\section{MLST analysis}

MLST analysis showed that isolate 1 was MLST sequence type 36 (ST36) that did not cluster with any of the clonal complexes previously observed (Rosales et al., 2015). Isolates 2 and 3 produced two different STs, ST30 and ST32, respectively, which clustered in the same clonal complex 1.

\section{WBC, GRA, LYM and MID counts}

The WBC count was higher in all of the experimental groups than in the control group on day 1, but it returned to near the initial level on day 2 (Fig. 1). Group E1 had a higher WBC count than the control group throughout the study. In Fig. 1 it can be seen that the WBC counts for Groups E2 and E3 between days 3 and 7 were visibly lower than the values obtained for the control group and Group E1. From day 14 the WBC count increased again. A similar trend was observed for the PMNL count (Fig. 2) and the LYM count (Fig. 3). The MID count had comparable values for all groups throughout the experiment (Fig. 4).

\section{$\mathrm{CD}^{+}, \mathrm{CD}^{+}, \mathrm{CD} 8^{+}$and $\mathrm{WC4}^{+}$percentages and $\mathrm{CD} 4: \mathrm{CD} 8$ positive ratio}

In Group E1, the $\mathrm{CD}^{+}$percentage (Fig. 5) was generally decreased throughout the study when compared to the control and the other experimental groups. In contrast, this percentage was higher, with significant differences at day 5, in Groups E2 and E3 than in the control group between days 3 and 5, and it increased again in Group E3 on days 14 and 28 (Fig. 5). 
Between days 2 and 4 , markedly increased values of $\mathrm{CD} 4^{+}$percentage were noted in the experimental groups as compared to the control group. After that the E1 values were comparable to the control (Fig. 6). E2 and E3 had higher values for days 5 to 14 with a significant difference between E3 and the control at day 6.

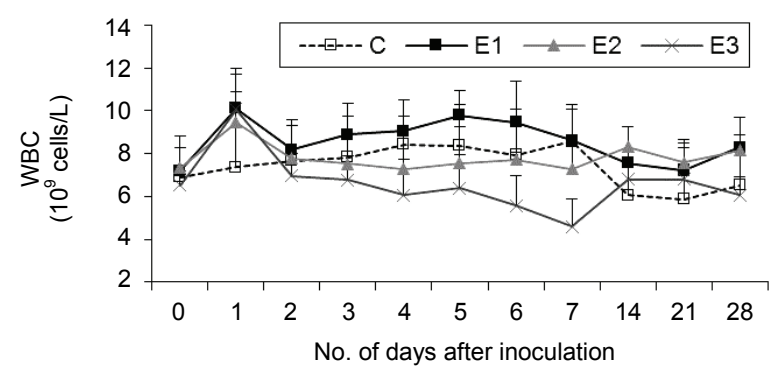

Fig. 1. White blood cell (WBC) counts of calves inoculated with three different field isolates of Mycoplasma bovis; E1: the group inoculated with isolate 1; E2: the group inoculated with isolate 2;

E3: the group inoculated with isolate 3; C: control group

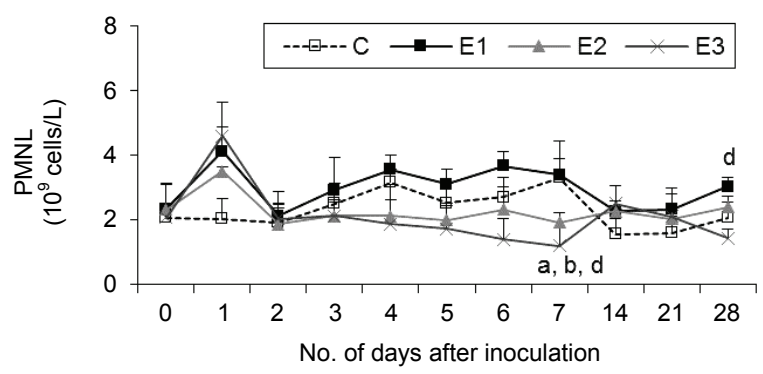

Fig. 2. Polymorphonuclear leukocyte (PMNL) count of calves inoculated with three different field isolates of Mycoplasma bovis (for group designations see legend to Fig. 1). a: significant differences at $\mathrm{P}<0.05$ between Group E2 and the control group; b: significant differences at $\mathrm{P}<0.05$ between Group E3 and the control group; d: significant differences at $\mathrm{P}<0.05$ between Groups E1 and E3

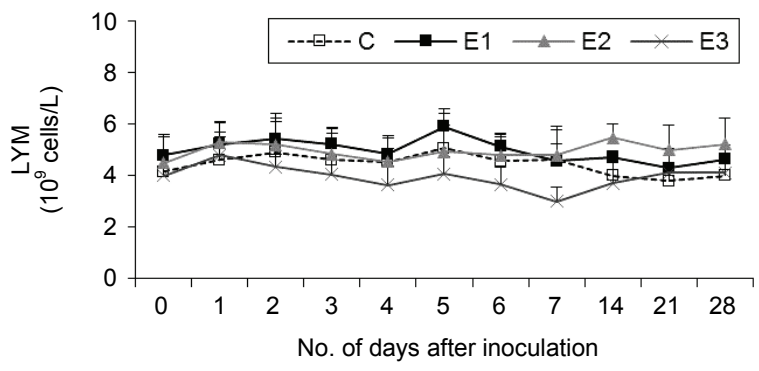

Fig. 3. Lymphocyte (LYM) count of calves inoculated with three different field isolates of $M$. bovis 


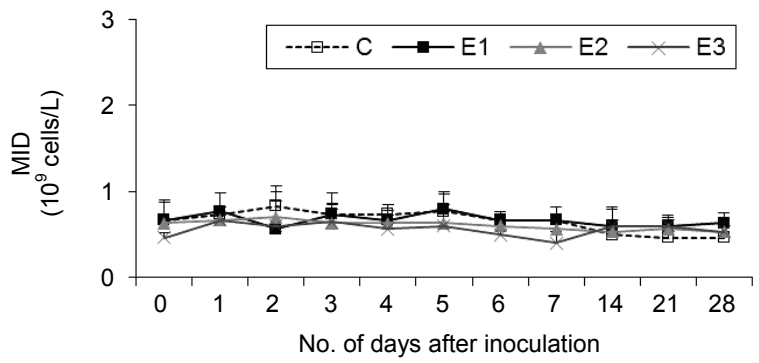

Fig. 4. Monocytes, eosinophil and basophil (MID) count of calves inoculated with three different field isolates of Mycoplasma bovis

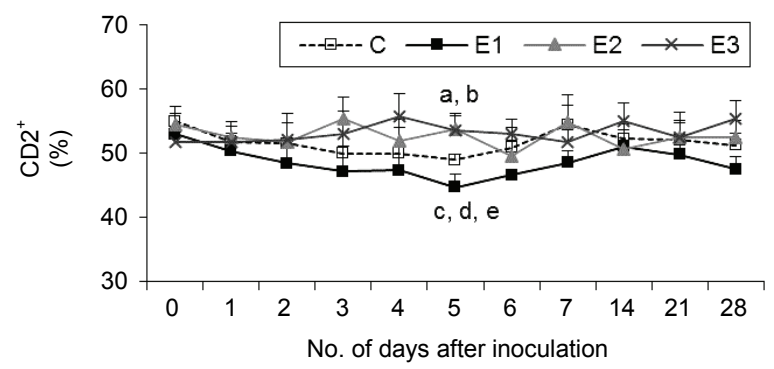

Fig. 5. CD2 ${ }^{+}$percentage of calves inoculated with three different field isolates of Mycoplasma bovis. a: significant differences at $\mathrm{P}<0.05$ between Group E2 and the control group; b: significant differences at $\mathrm{P}<0.05$ between Group E3 and the control group; c: significant differences at $\mathrm{P}<$

0.05 between Group E1 and the control group; d: significant differences at $\mathrm{P}<0.05$ between

Groups E1 and E3; e: significant differences at $\mathrm{P}<0.05$ between Groups E1 and E2

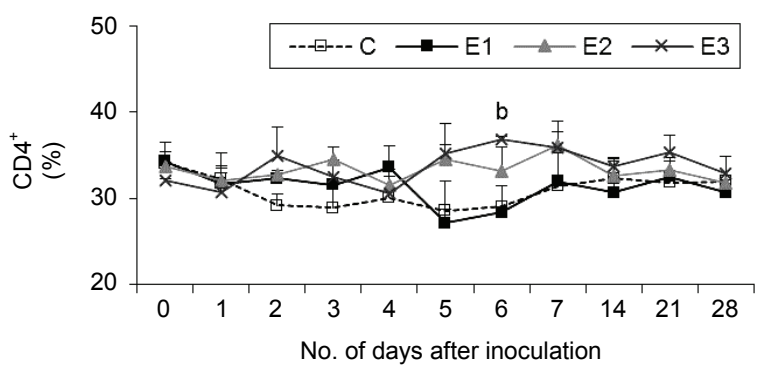

Fig. 6. $\mathrm{CD}^{+}$percentage of calves inoculated with three different field isolates of Mycoplasma bovis. b: significant differences at $\mathrm{P}<0.05$ between Group E3 and the control group

Group E1 had decreased values in $\mathrm{CD} 8^{+}$percentage when compared with the other groups of animals for most of the experiment (Fig. 7). A slightly increased response regarding $\mathrm{CD} 8^{+}$percentage was reported in Groups E2 and E3 until day 6, with a significant increase in the control group and Group E3 at day 14. 
In the control group the $\mathrm{WC}^{+}$percentage (Fig. 8) fluctuated with the lowest value occurring on day 4 and the highest on day 7. Group E1 had low values on days 2 and 7 with significant differences between this group and the control group. Group E3 appeared to have a more stable $\mathrm{WC}^{+}$response throughout the study, while in Group E2 the $\mathrm{WC}^{+}$percentage increased between days 6 and 14, with a marked rise on day 28 which gave a significant difference in comparison with Group E3.



Fig. 7. $\mathrm{CD}^{+}$percentage of calves inoculated with three different field isolates of Mycoplasma bovis. a: significant differences at $\mathrm{P}<0.05$ between Group E2 and the control group; c: significant differences at $\mathrm{P}<0.05$ between Group $\mathrm{E} 1$ and the control group

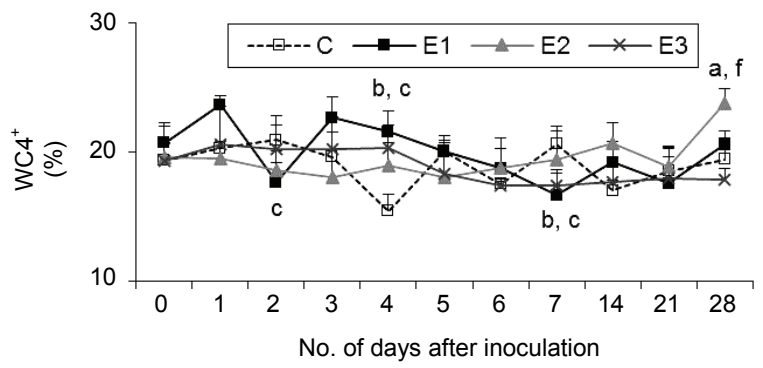

Fig. 8. $\mathrm{WC4}^{+}$percentage of calves inoculated with three different field isolates of Mycoplasma bovis. a: significant differences at $\mathrm{P}<0.05$ between Group $\mathrm{E} 2$ and the control group; $\mathrm{b}$ : significant differences at $\mathrm{P}<0.05$ between Group E3 and the control group; $\mathrm{c}$ : significant differences at $\mathrm{P}<$ 0.05 between Group E1 and the control groups; f: significant differences at $\mathrm{P}<0.05$ between Groups E2 and E3

The CD4:CD8 positive ratio was generally higher in Groups E1 and E2 (Fig. 9) than in the control group from day 2 until the end of the study, with the exception of days 5 and 6 for Group E1 and days 4 and 28 for Group E2. In Group E3 this ratio was visibly higher than in the control group on days 2, 5, 6 and 7. At the remaining days of the study the values for this group were comparable or slightly lower than those in the control group (Fig. 9). 


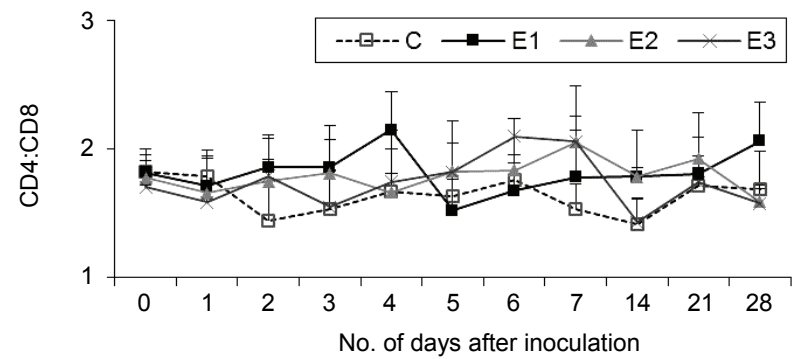

Fig. 9. CD4:CD8 positive T cell ratio of calves inoculated with three different field isolates of $M y$ coplasma bovis

\section{Discussion}

Previously Dudek et al. (2013) used a similar experimental design which demonstrated the immunomodulatory effect of $M$. bovis in calves. In response to that $M$. bovis infection both a stimulation and a suppression of immunity in the affected calves was observed, depending on the mycoplasma isolate used. In this study, a considerable increase in the WBC count in all of the challenged groups of calves was observed on day 1 which probably resulted from a stimulation of neutrophil production and recirculation. The subsequent decrease to day 7 of these cells in Groups E2 and E3 may be due to neutrophil influx into the target tissues (Salmon and Higgs, 1987), resulting from a stimulating effect exerted on these cells by a powerful chemoattractant, leukotriene $\mathrm{B}_{4}\left(\mathrm{LTB}_{4}\right)$. The stimulating effect of $\mathrm{LTB}_{4}$ has already been reported and its mechanism confirmed; however, previously it was shown that the $\mathrm{LTB}_{4}$ status is decreased in seropositive cattle (Dudek et al., 2011b). LTB $_{4}$ also has a strong chemotactic activity toward eosinophils (Traczyk and Trzebski, 2001).

In Group E1, challenged with an isolate from mastitis, both the WBC and PMNL counts were consistently higher than in the controls for most of the study. It is therefore possible that this isolate could effectively stimulate neutrophil recirculation from the bone marrow to the blood vessels. The inverse effect seen in Groups E2 and E3 could be due to the different site of origin of the other M. bovis isolates used for challenge. The similar action of these two isolates on the neutrophils may be explained by their close relatedness, being in the same clonal complex as shown by MLST typing (Rosales et al., 2015).

An in vitro study demonstrated that the recall response to $M$. bovis was related to both $\mathrm{CD}^{+}$and $\mathrm{CD} 8^{+}$expression (Vanden Bush and Rosenbusch, 2003). In this study a distinct increase of the $\mathrm{CD}^{+}$cells was observed in all experimental groups, but it was more marked in the group inoculated with the isolate from bovine fetal stomach contents. This stimulation could be related to an induction of mechanisms responsible for mycoplasma elimination, such as macrophage ac- 
tivation and some co-operative cytokine release. A prominent role of $\mathrm{CD}^{+}{ }^{+}$response in infections caused by M. bovis and other Mycoplasma species such as M. agalactiae in goats (Rodríguez et al., 2000) and M. pulmonis in mice (Jones et al., 2002) was already discussed. The most evident depletion of $\mathrm{CD} 8^{+}$cells was observed for the mastitic isolate which may be linked to the target tissues and their local cytotoxic activity. In contrast, a slight stimulation of the $\mathrm{CD} 8^{+}$response was shown in the other experimental groups, which may suggest a greater recruitment of these cells in the bone marrow and thymus, resulting in an increase in the peripheral T-cytotoxic suppressor cells. In Groups E2 and E3, there was a lack of a distinct B-cell response, although the response was more marked for the E2 calf pneumonia isolate where increases in the $\mathrm{WC}^{+}$percentage were observed on days 14 and 28. In this study, the course of the B-cell response could be associated with the production of specific antibodies to M. bovis which were detected in our previous study in the experimental calves from day 21 for Group E2 and from day 14 for Group E3 (Dudek et al., 2013). In contrast, the $\mathrm{WC}^{+}$count increase was generally stimulated in the calves inoculated with the E1 mastitic isolate and specific antibodies to M. bovis were detected from day 21. However, the production of these antibodies was the most delayed and less intense in this group than in the other experimental groups (Dudek et al., 2013).

In this study the CD4:CD8 positive $\mathrm{T}$ cell ratio was generally increased in the group challenged with the isolate of cow mastitis origin as a result of increased $\mathrm{CD} 4^{+}$cell percentage during the first days of the study and a distinct decline of the $\mathrm{CD} 8^{+}$cells later in the study. An increased CD4:CD8 positive T cell ratio was also observed in the group inoculated with the isolate obtained from calf pneumonia, probably as a consequence of $\mathrm{CD}^{+}$stimulation. This would also account for the fact that the CD4:CD8 positive T cell ratio obtained for the E3 fetal stomach content isolate was visibly higher than that found in the controls on days 2, 6 and 7. Previously the importance of this parameter in the evaluation of the immune status of calves experimentally infected with Mannheimia haemolytica A1 leukotoxin (Bednarek et al., 2009) or following a commercial vaccination (Dudek et al., 2009) was demonstrated. Additionally, CD4:CD8 imbalance could be a useful indicator of intensified or diminished T-cell immune response, and this information may be useful for diagnosis.

The immune response to $M$. bovis varies with the isolate used, which may be related to the source of the isolate, the molecular type or the surface protein profile. Further work should analyse the variable surface proteins expressed by these isolates during infection. However, this study has demonstrated that the main host responses to $M$. bovis infections are the stimulation of T-helper cells and the enhancement of response regarding B lymphocytes. It is worth noting that these responses were evaluated in the peripheral blood of calves but they may, at least partially, reflect changes in leukocyte subsets in the secondary lymphoid organs as well. 


\section{References}

Ayling, R. D., Bashiruddin, S. E. and Nicholas, R. A. J. (2004): Mycoplasma species and related organisms isolated from ruminants in Britain between 1990 and 2000. Vet. Rec. 155, 413-416.

Bednarek, D., Urban-Chmiel, R., Dudek, K. and Szymańska-Czerwińska, M. (2009): Evaluation of peripheral blond leukocyte subpopulations by flow cytometry in calves treated with Mannheimia haemolytica leukotoxin. Bull. Vet. Inst. Puławy 53, 199-203.

Dudek, K. and Bednarek, D. (2012): Last survey of Mycoplasma bovis prevalence in Polish cattle affected with respiratory syndrome. Bull. Vet. Inst. Puławy 56, 447-451.

Dudek, K., Bednarek, D., Ayling, R. D. and Szacawa, E. (2013): Immunomodulatory effect of Mycoplasma bovis in experimentally infected calves. Bull. Vet. Inst. Puławy 57, 499-506.

Dudek, K., Bednarek, D. and Szacawa, E. (2011a): Evaluation of immune response in seropositive cattle for Mycoplasma bovis. Bull. Vet. Inst. Puławy 55, 631-634.

Dudek, K., Bednarek, D. and Szacawa, E. (2011b): Stimulating effect of Mycoplasma bovis infection on proinflammatory response in infected cattle. Bull. Vet. Inst. Puławy 55, 599-602.

Dudek, K., Bednarek, D. and Szymańska-Czerwińska, M. (2010): Acute phase response in calves as a result of experimental challenge with Mycoplasma bovis. Bull. Vet. Inst. Puławy 54, $517-520$.

Dudek, K., Szymańska-Czerwińska, M., Bednarek, D. and Niemczuk, K. (2009): Effect of intranasal PI3V and BRSV administration on the alternations in selected peripheral blood leukocyte subpopulations in calves. Bull. Vet. Inst. Puławy 53, 557-561.

Jones, H. P., Tabor, L., Sun, X., Woolard, M. D. and Simecka, J. W. (2002): Depletion of CD8 ${ }^{+}$T cells exacerbates $\mathrm{CD}^{+}$Th cell-associated inflammatory lesions during murine mycoplasma respiratory disease. J. Immunol. 168, 3493-3501.

Jungi, T. W., Krampe, M., Sileghem, M., Griot, C. and Nicolet, J. (1996): Differential and strainspecific triggering of bovine alveolar macrophage effector functions by mycoplasmas. Microb. Pathog. 21, 487-498.

Le Grand, D., Calavas, D., Brank, M., Citti, C., Rosengarten, R., Bézille, P. and Poumarat, F. (2002): Serological prevalence of Mycoplasma bovis infection in suckling beef cattle in France. Vet. Rec. 150, 268-273.

McAuliffe, L., Ellis, R. J., Lawes, J. R., Ayling, R. D. and Nicholas, R. A. J. (2005): 16S rDNA PCR and denaturing gradient gel electrophoresis; a single generic test for detecting and differentiating Mycoplasma species. J. Med. Microbiol. 54, 731-739.

Nicholas, R. A. J. and Ayling, R. D. (2003): Mycoplasma bovis: disease, diagnosis and control. Res. Vet. Sci. 74, 105-112.

Nicholas, R. A. J. and Baker, S. (1998): Recovery of mycoplasmas from animals. In: Miles, R. and Nicholas, R. (eds) Methods in Molecular Biology. Mycoplasma Protocols. Humana Press, Totowa. pp. 37-43.

Pardon, B., De Bleecker, K., Dewulf, J., Callens, J., Boyen, F., Catry, B. and Deprez, P. (2011): Prevalence of respiratory pathogens in diseased, non-vaccinated, routinely medicated veal calves. Vet. Rec. 169, 278.

Radaelli, E., Luini, M., Loria, G. R., Nicholas, R. A. J. and Scanziani, E. (2008): Bacteriological, serological, pathological and immunohistochemical studies of Mycoplasma bovis respiratory infection in veal calves and adult cattle at slaughter. Res. Vet. Sci. 85, 282-290.

Rodríguez, F., Sarradell, J., Poveda, J. B., Ball, H. J. and Fernández, A. (2000): Immunohistochemical characterization of lung lesions induced experimentally by Mycoplasma agalactiae and Mycoplasma bovis in goats. J. Comp. Pathol. 123, 285-293.

Rosales, R. S., Churchward, C. P., Schnee, C., Sachse, K., Lysnyansky, I., Catania, S., Iob, L., Ayling, R. D. and Nicholas, R. A. J. (2015): Global MLST analysis of Mycoplasma bovis isolates reveals two main population clusters. J. Clin. Microbiol. 53, 789-794. 
Salmon, J. A. and Higgs, G. A. (1987): Prostaglandins and leukotrienes as inflammatory mediators. Br. Med. Bull. 43, 285-296.

Tenk, M., Stipkovits, L. and Hufnagel, L. (2004): Examination of the role of Mycoplasma bovis in bovine pneumonia and a mathematical model for its evaluation. Acta Vet. Hung. 52, 445-446.

Traczyk, W. Z. and Trzebski, A. (2001): Human Physiology with Elements of Applied and Clinical Physiology [in Polish]. 3rd edition. Wydawnictwo Lekarskie PZWL, Warsaw.

Vanden Bush, T. J. and Rosenbusch, R. F. (2002): Mycoplasma bovis induces apoptosis of bovine lymphocytes. FEMS Immunol. Med. Microbiol. 32, 97-103.

Vanden Bush, T. J. and Rosenbusch, R. F. (2003): Characterization of the immune response to $M y$ coplasma bovis lung infection. Vet. Immunol. Immunopathol. 94, 23-33.

Wiggins, M. C., Woolums, A. R., Hurley, D. J., Sanchez, S., Ensley, D. T. and Donovan, D. (2011): The effect of various Mycoplasma bovis isolates on bovine leukocyte responses. Comp. Immunol. Microbiol. Infect. Dis. 34, 49-54. 